\title{
Recent Advances in Examination of Vocal Fold Vibration
}

\author{
Jin-Choon Lee ${ }^{1}$ iD and Inho Bae ${ }^{2}$ (D) \\ 2Department of Speech \& Language Pathology, Kosin University, Busan, Korea \\ 성대진동검사의 최신 지견 \\ 이진춘 ${ }^{1}$, 배인호 $^{2}$ \\ 부산대학교 의과대학 이비인후과학교실, ${ }^{1}$ 고신대학교 언어치료학과 ${ }^{2}$
}

'Department of Otorhinolaryngology-Head and Neck Surgery, College of Medicine, Pusan National University, Yangsan, Korea

Human vocal cords vibrate as quickly as 100-250 times per second, so it is impossible to observe them with normal endoscopic diagnostic equipment. High-speed videolaryngoscopy (HSV) allows the visualization of non-periodic vibratory motion of vocal fold beyond the limitation of videostroboscopy. New developed post-processing methods that converts HSV to two-dimensional videokymography (2D VKG) using U-medical image-processing software can provide quantitative information on vocal fold mucosa vibration. Multifunctional laryngeal examination system is composed of 3 kinds of examinations such as HSV, 2D scanning digital kymography (2D DKG) and line scanning digital kymography (DKG). Evaluation of entire vocal cord vibratory pattern in each cord is possible using 2D DKG and a faster and more reliable quantitative information can be obtained. As this system is used in clinical and research, it is expected to bring much advances to the diagnosis of voice disorders. In this review, I will introduce the principles and advantages on examination of the vocal fold vibration, which is in the spotlight recently, and proceed with the literature review.

Keywords Vocal cords; Vibration; Stroboscopy; Kymography.

\section{서 론}

사람의 성대는 1초에 100 250회 정도로 빠르게 진동하기 때문에 정상적인 내시경 진 단장비로는 관찰하기가 불가능하다. 1895년 Oretel이 탈봇의 원리를 이용하여 성대 진동 을 느린 화면으로 관찰한 이래로 많은 검사 기구들이 개발되어 성대의 진동을 관찰하려 는 시도가 현재에도 진행되고 있다[1-3]. 현재까지도 임상에서 가장 많이 사용되는 후두 스트로보스코피(laryngeal stroboscopy)가 있지만 심한 애성이 있어 3 5초 이상의 안 정적인 발성이 어려운 경우는 검사가 부적합하다.

이때 사용할 수 있는 방법이 초당 2000 5000 프레임으로 성대의 진동을 관찰할 수 있는 초고속 비디오 후두내시경 검사(high-speed videolaryngoscopy, HSV)이다. 뿐만 아니라 초고속 영상을 촬영한 뒤 이미지 처리과정을 통하여 얻을 수 있는 카이모그래피 (kymography)는 성대의 불규칙한 진동의 관찰도 가능하게 한다[1]. 카이모그래피는 비 디오 카이모그래피(videokymography, VKG)와 디지털 카이모그래피(digital kymogra-
Received May 12, 2020

Revised June 8, 2020

Accepted June 9, 2020

Corresponding Author Inho Bae, PhD

Department of Speech \& Language Pathology,

Kosin University,

194 Wachi-ro, Yeongdo-gu, Busan 49104, Korea

Tel +82-51-990-2436

Fax $+82-0504-423-7898$

E-mail voicebae@kosin.ac.kr

ORCID iDs

Jin-Choon Lee (D)

https://orcid.org/0000-0002-4056-8763 Inho Bae (D)

https://orcid.org/0000-0003-4432-5192

This is an Open Access article distributed under the terms of the Creative Commons Attribution Non-Commercial License (https://creativecommons.org/ licenses/by-nc/4.0) which permits unrestricted non-commercial use, distribution, and reproduction in any medium, provided the original work is properly cited. 
phy, DKG)로 나눌 수있다. 비디오 카이모그래피는 비디오 카 메라만으로 측정한 영상으로, 라인 스캔 비디오 카이모그래 피와 평면 스캔 비디오 카이모그래피가 있으며, 디지털 카이 모그래피는 초고속 비디오 내시경 영상을 촬영한 뒤, 이미지 처리 과정을 통하여 비디오 카이모그래피와 거의 유사한 영 상을 얻는 방식이며, 이 방식에도 라인 스캔 디지털 카이모그 래피와 평면 스캔 디지털 카이모그래피가 있다. 이러한 초고 속 후두내시경 영상을 이용한 평면 스캔 디지털카이모그래프 (2D DKG) 영상 생성을 통하여 위상대칭지수(Phase Symmetry Index), 진폭대칭지수(Amplitude Symmetry Index), 개방지수(open quotient), 폐쇄지수(close quotient) 등의 성 대 진동의 정량적인 정보를 얻을 수 있었다[2]. 또한, 최근에 새롭게 개발된 초고속 디지털 카메라로 촬영한 영상을 이용 하여 $\mathrm{DKG}$ 와 $2 \mathrm{D} \mathrm{DKG}$ 를 동시에 획득함으로써 다양한 형태 의 이미지를 실시간으로 동시에 제공할 수 있었고, 형태학적 및 기능적 진동 패턴도 분석할 수 있었다[3].

최근에는 앞에서 언급한 고속 비디오 후두 내시경 검사, $2 \mathrm{D}$ 디지털 카이모그래피 및 라인 스캐닝 디지털 카이모그래피 를 실시간으로 동시에 검사가 가능한 혁신적인 기술인 다기능 후두성능검사시스템(multifunctional laryngeal examination system)이 개발되어 종합적으로 성대 진동을 관찰할 수 있게 되었으며, 이는 다양한 성대 진동 장애 병변의 진단에 이용될 예정이다.

본 논문에서는 여러 가지 최신의 성대 진동 검사들에 대해 알아보고자 한다.

\section{본 론}

최근에 많이 이용되고 있는 여러가지 성대진동검사에 대해 알아보고자 한다.

\section{후두 스트로보스코피(Laryngeal stroboscopy)}

현재 사용되고 있는 후두 스트로보스코피는 전기 전자 기 술의 발달로 성대를 직접 눈으로 관찰하는 것이 아니라 내시 경과 Charge Coupled Device(CCD) 카메라를 통해 들어온 데 이터가 모니터로 출력되는 영상에서 성대의 느린 움직임을 관 찰한다. 2010년도에 발표된 연구에 의하면 실제의 움직임은 없으나 움직임이 있는 것으로 인식되는(최소한 $17 \mathrm{~Hz}$ 이상으 로 디스플레이가 가능한) 가현 운동(apparent motion) 지각 과 화면에 디스플레이 되는 영상을 주사할 때 깜빡임 현상이 나타나는 플리커(flicker) 현상이 서로 다른 시지각(visual perception) 현상으로 이러한 원리가 최근 스트로보스코피의 원 리로 인정받고 있다[4]. 최소 $50 \mathrm{~Hz}$ 이상의 속도로 영상을 주사
해야만 화면의 깜박임을 눈으로 지각하지 못한다는(flikerless) 원리가 내포되어 있다고 할 수 있다. 오랫동안 후두 스트 로보스코피를 구현하는 방식으로 기본주파수에 맞게 단속 광원을 조절하여 스트로보 효과를 이용하는 방법을 이용하 여 왔다[5]. 이는 대부분의 스트로보스코피가 이용하는 방법인 데, 진동하는 성대를 촬영할 때 성대 진동 주기와 동기화된 고 속 발광 단속 광원을 비춰주면 나타나는 영상은 성대의 실제 움직임이 아니라 발광되는 순간의 성대의 모습이 느리게 관 찰된다. 이때 후두 스트로보스코피의 동기화 신호 추출은 전 기성문파(electroglottography) 신호를 이용하는 방식이 가장 널리 사용되고, 그 외 음성 혹은 진동검출기를[6] 이용하는 방 식이 소개되기도 하였다. 다른 방법으로는 기본 주파수를 이 용하여 셔터스피드를 조절하여 단속 광원이 아닌 연속 광원 을 이용하여 스트로보 효과를 나타내는 방법이다. 2000년도 에 들어 여러 연구에서 연속 광원을 이용하여 셔터 스피드를 성대 진동과 동기화하면 새롭게 스트로보 효과를 구현할 수 있다고 보고하였다[7]. 하지만, 특정 후두에 대한 시각적이고 객 관적인 평가는 스트로보스코피 이미징을 사용하여서는 신뢰 할 수 없어서 후두 고속 비디오 내시경 검사 및 기타 대체 이 미징 방식을 일상적인 임상 실습에 통합하여 음성 장애 관리 를 향상시키는 추가 연구가 필요하다[7]. Fig. 1은 초당 30 프레 임(fps)을 캡처하여 각 진동주기의 다른 지점에서 이미지를 모아서 편집한 성대 진동의 슬로우 모션을 보여주는 스트로 보스코피 영상이다.

\section{초고속 비디오 후두내시경 검사(High-speed videolaryngoscopy)}

1990년대 연구목적으로 도입된 초고속 비디오 후두내시경 검사 $(\mathrm{HSV})$ 는 성대 진동 운동의 관찰을 위한 가장 정확한 도 구로 간주되었다. 그러나 상업적 $\mathrm{HSV}$ 시스템은 해결되지 않 은 기술적, 평가방법론적 한계와 HSV의 유효성 및 임상적 관 련성에 관한 정보 부족으로 인해 임상적으로는 널리 사용되

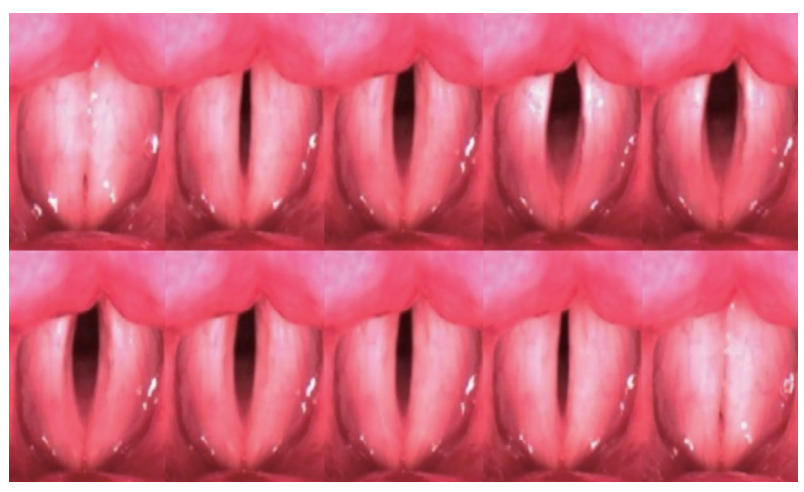

Fig. 1. Montage of stroboscopic images obtained from successive points in several glottal cycles. 
지 않았다[8]. HSV로 촬영하여 얻는 초고속 디지털 영상(highspeed digital imaging, HSDI)은 최근에 가장 널리 사용되는 점막 운동의 시각화 방법이 되었다. 후두 스트로보스코피 검 사로 생성된 착시와는 달리 $\mathrm{HSDI}$ 의 높은 프레임 속도는 점막 파를 상세하게 시각화 하여 단일 성대 주기에서 여러 이미지를 캡처한다[9]. Fig. 2는 정상 성인 남성에서 발성 시 초당 3000 프 레임으로 촬영된 성대의 HSV 영상소견이다[2]. 최근의 보고에 의하면 HSV 데이터를 분석하는 데 사용된 방법이 다양한 성 대 병리를 가진 환자의 성대 진동의 특성을 문서화하고 진동 장애의 심각성을 추정하기 위해 진동 장애를 조사하는 데 매 우 유용할 수 있음을 입증했다[10-13]. 대부분의 초고속 비디 오 후두내시경 검사는 라인 스캐닝 카이모그래피 기능을 사 용할 수 있도록 소프트웨어를 제공해 주므로 여러 주기에 걸 쳐 점막파동 및 주기성, 대칭성을 시각적으로 빠르게 관찰할 수 있어 HSV와 병행하여 효율적으로 사용되고 있다. 2017년 보고에서 성대 진동의 모든 단계에 대한 직렬 HSV 이미지를 U-medical 이미지 처리 소프트웨어를 사용하여 스캐닝 방 법에 의해 변환시켰는데. 이러한 후 처리된 $2 \mathrm{D} \mathrm{DKG}$ 이미지 는 다양한 진동 위상을 포함하여 성대 점막 진동에 대한 정량
적 정보를 제공할 수 있었다[2].

새롭게 획득된 2D DKG와 DKG 사이의 진폭 대칭 지수, 위상 대칭 지수, 개방 지수 및 폐쇄 지수의 차이를 분석하였고 $2 \mathrm{D} \mathrm{DKG}$ 와 $\mathrm{DKG}$ 에서 성대 진동 운동의 정량적 파라미터 사 이에는 통계적 차이가 없다는 결과를 보여주었다[2]. $\mathrm{HSDI}$ 에 의 해 기록된 더 높은 프레임 속도와 많은 이미지 수는 분석에 더 많은 시간과 비용이 소요되지만 HSDI에 의해 생성된 시 각화는 주파수에 독립적이므로 비주기적인 병리학적 성대의 진동을 진단하는 데는 더 효과적이다[9]. Table 1은 여러가 지 성대 진동 검사 기기의 차이점을 보여주고 있다. Sekimoto 등[14]은 $1200 \mathrm{fps}$ 의 기록 속도로 비교적 저렴한(3000 달러) 고속 촬영 시스템이 제안되었지만 상대적으로 해상도가 낮은 단점이 지적되었다.

\section{카이모그래피(Kymography)}

디지털 카이모그래피(DKG)의 출현과 함께 HSDI는 시스템 이 대폭 개선되었다. 이는 성대 진동을 보다 효과적으로 연구 하는 능력과 카이모그램을 통한 점막 진동 파라미터와 진동 을 정량화하는 능력이 도입되었기 때문이다. DKG는 2000

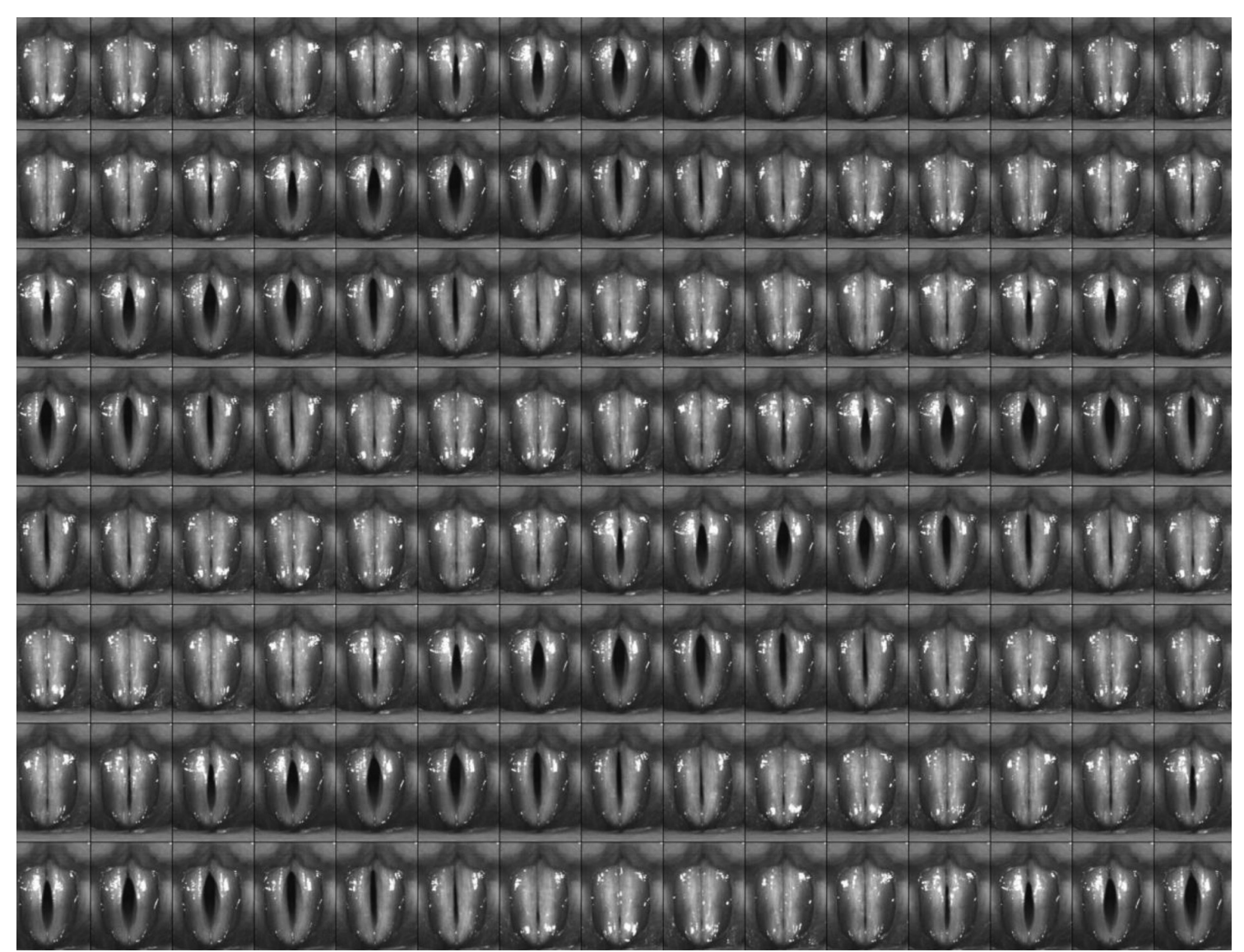

Fig. 2. The serial high-speed videoendoscopy images for all phases of vocal fold vibratory movement. Adapted from Cha et al. J Korean Soc Laryngol Phoniatr Logop 2017;28(2):89-95 [2]. 
Table 1. Comparison of available current mucosal wave imaging techniques

\begin{tabular}{|c|c|c|c|c|c|}
\hline Technique & Purpose & $\begin{array}{l}\text { Compared } \\
\text { cost }\end{array}$ & $\begin{array}{l}\text { Frame } \\
\text { rate }\end{array}$ & $\begin{array}{l}\text { Compared } \\
\text { resolution }\end{array}$ & Best use \\
\hline Stroboscopy & $\begin{array}{l}\text { Visualization of only periodic vocal folds vibration, } \\
\text { mucosal wave patterns }\end{array}$ & 1 & $20-30 \mathrm{fps}$ & 3 & First visit evaluation \\
\hline HSV & $\begin{array}{l}\text { More detailed visualization of periodic and aperiodic vocal } \\
\text { folds vibration, mucosal wave patterns }\end{array}$ & 2 & $\begin{array}{l}6,000-8,000 \\
\text { lines/s }\end{array}$ & 2 & $\begin{array}{l}\text { Supplement to } \\
\text { stroboscopy }\end{array}$ \\
\hline VKG & $\begin{array}{l}\text { Qualitative and quantitative description of periodic and } \\
\text { aperiodic vocal folds vibration, mucosal wave patterns }\end{array}$ & 3 & $\begin{array}{l}3,000-4,000 \\
\text { fps }\end{array}$ & 1 & $\begin{array}{l}\text { Supplement to } \\
\text { stroboscopy }\end{array}$ \\
\hline EGG & $\begin{array}{l}\text { Describes duration, coordination, relative contact patterns } \\
\text { withinglottal cycle; detects onset ofglottal opening, analyzes } \\
\text { irregularvibratory pattern }\end{array}$ & 0 & $\mathrm{n} / \mathrm{a}$ & $\mathrm{n} / \mathrm{a}$ & $\begin{array}{l}\text { In tandem with } \\
\text { stroboscopy, VKG, } \\
\text { or HSD }\end{array}$ \\
\hline
\end{tabular}

VKG: videokymography, HSV: high-speed videolaryngoscopy, EGG: electroglottography.

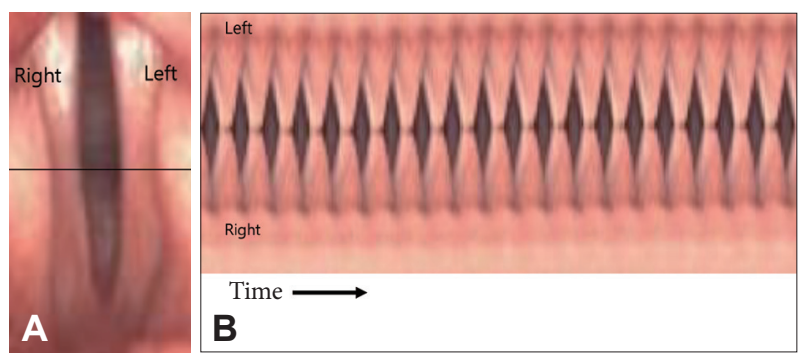

Fig. 3. It shows the vibratory pattern of nearly periodic type. A: Image of line-scan placement at the widest section of the glottis in DKG. B: Kymogram of periodic vibration obtained using DKG. DKG: digital kymography.

$5000 \mathrm{fps}$ 속도로 HSDI가 얻은 풀 프레임 이미지를 사용하고 컴퓨터 소프트웨어로 분석한다[8,9,15,16]. 이 소프트웨어는 비디오의 연속 프레임 각각에서 추출된 성문 축(glottal axis)에 직각인 픽셀 라인을 사용자가 원하는 대로 선택할 수 있다(Fig. 3A). 영상 저장 후 나오는 라인 추출은 픽셀 라인이 선택되기 전에 각도 보정 및 후두개 또는 피열 연골에 의한 카 메라 시야의 막힘 여부 확인을 가능하게 해주고 픽셀 라인이 한번 추출되면, 프레임 번호에 기초하여 연속적으로 나란히 구성된다. 이것은 점막 파의 움직임을 시각화 하여 개방 및 폐 쇄 위상, 주기성, 좌우 대칭, 위상차 및 진폭을 보여주는 카 이모그램(kymogram)을 만든다(Fig. 3B)[17]. HSDI와 함께 사용되는 DKG는 HSDI만으로 프레임 단위의 성대 사이클을 분석하는 것보다 점막 파 매개 변수를 설명하는 정량적 및 정 성적 결과를 얻을 수 있는 보다 빠르고 안정적인 방법을 제공 한다. $\mathrm{VKG}$ 는 $\mathrm{HSDI}$ 와 결합된 $\mathrm{DKG}$ 검사 혹은 $\mathrm{HSDI}$ 단독 검 사 보다 성대 점막 진동을 측정하는데 보다 효율적인 측정 방 법이다. $\mathrm{VKG}$ 는 $\mathrm{DKG}$ 와 달리 녹화 전에 단일 픽셀 라인을 선 택해야 하고 $\mathrm{VKG}$ 로 기록된 단일 픽셀 라인은 $\mathrm{HSDI}$ 또는 $\mathrm{DKG}$ 로 $\mathrm{HSDI}$ 로 기록한 일반적인 풀 프레임 이미지보다 해상도가 횔씬 낮다[17]. VKG는 HSDI 만큼 많은 데이터를 기록하지 않기 때문에 $\mathrm{CCD}$ 에 의해 기록된 하나의 픽셀 라인의 낮은

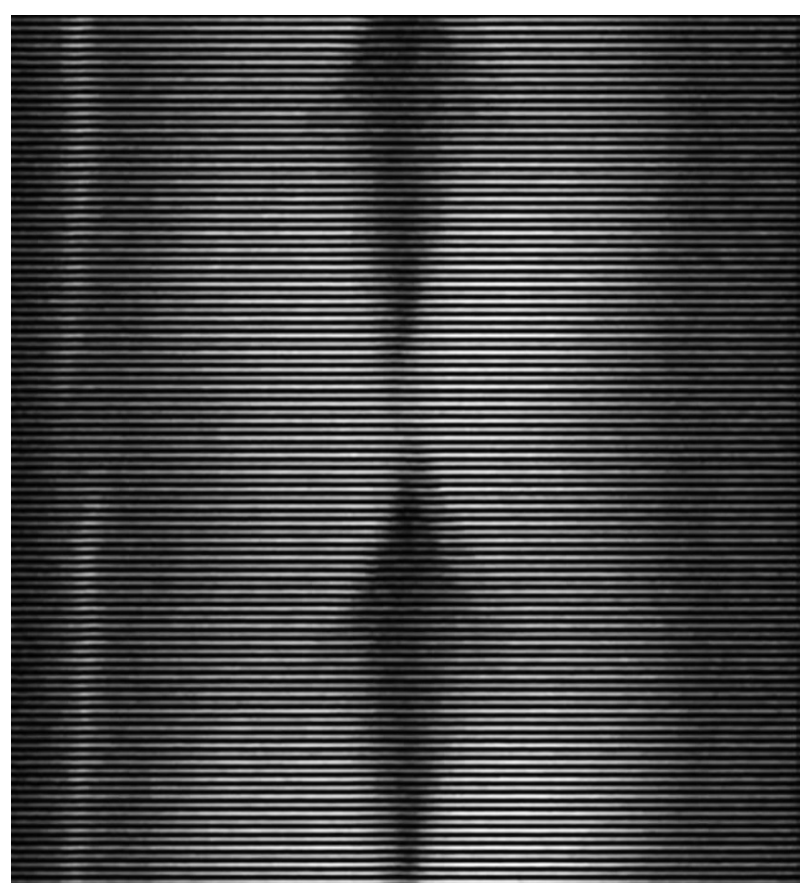

Fig. 4. VKG image of vocal folds with asymmetrical vibration. VKG: videokymography.

해상도의 프레임 비율은 실질적으로 증가할 수 있다. $\mathrm{VKG}$ 에 사용되는 $\mathrm{CCD}$ 의 프레임 속도는 거의 $8000 \mathrm{fps}$ 에 달한다 [18,19]. VKG는 HSDI 보다 높은 프레임 속도를 갖기 때문에 성대 주기 사이클 당 더 많은 사진을 기록할 수 있어 보다 정 확한 카이모그램 및 점막파 매개 변수 분석이 가능하다(Fig. 4). 2016년엔 Wang 등[20]에 의해 새로운 VKG 시스템이 개발 되어 전체 성대의 점막 진동 패턴과 개방 및 폐쇄 지속 시간 의 검사가 용이하게 되었다. 또한 이 시스템은 진폭 및 위상의 대칭과 내측 피크 및 측면 피크의 모양을 평가할 수 있는 기 능을 가지고 있어(Fig. 5) 급성 후두염 환자에서 성대의 진동 을 평가하는 향상된 능력을 보여주었다(Figs. 6, 7)[20]. 최근 에는 Kang 등[3]에 의해 초고속 비디오 후두내시경검사를 기 



Fig. 5. Characteristic VKG images generated by the new VKG system during phonation. A: The mucosal wave pattern of the entire vocal folds was captured during a single examination. B: The symmetry of the amplitude (arrow) could be assessed. C: The closing (a) and opening (b) durations could be differentiated. D, E: The shape of the medial (arrow) and lateral peaks (arrow) could be assessed. VKG: videokymography
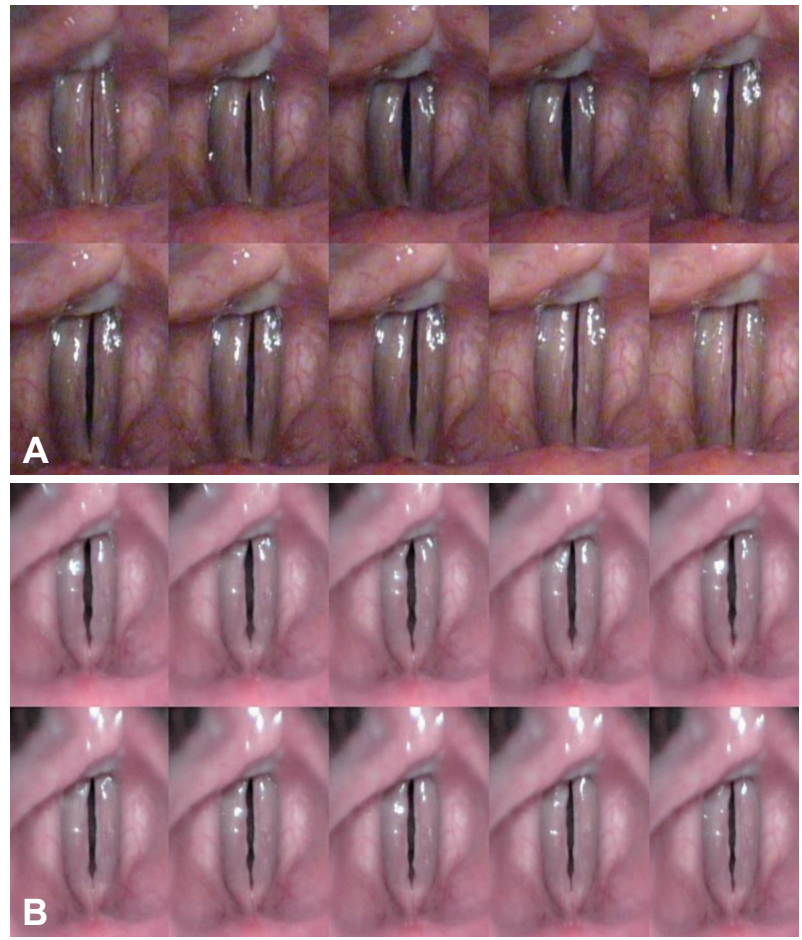

Fig. 6. Images obtained by laryngeal videostroboscopy (A) and the new VKG system (B) at the pretreatment status. VKG: videokymography.

반으로 하여 후두경 소견과 디지털 카이모그래피, 2D 평면 카 이모그래피를 동시에 관찰할 수 있는 시스템을 개발되었다. 이 기기를 이용하면 성대 전체의 진동을 분석할 수 있었고, 특 징적으로 이 시스템의 2D VKG는 초당 32400라인과 25프레 임을 보여주어 한 라인만 특별하게 관찰되는 라인 스캐닝 비 디오 카이모그래피와는 차별화하였다. 픽셀 수에 따라 이미 지의 프레임수가 다르게 나타났고 2D DKG에서는 2픽셀 라 인 스캐닝에서 정량적 평가가 유용하였다(Fig. 8)[3]. 또한 이 러한 시스템을 통해 후두내시경 검사로는 정확한 관찰이 어 려운 좌측 성대 반흔 환자에서 $\mathrm{DKG}$ 와 $2 \mathrm{D} \mathrm{VKG}$ 를 이용한 검사로 양측 성대 진동의 차이를 정확히 확인할 수 있었다 (Fig. 9). 2019년도엔 Bae 등[21]이 2D DKG가 이중음성의 진
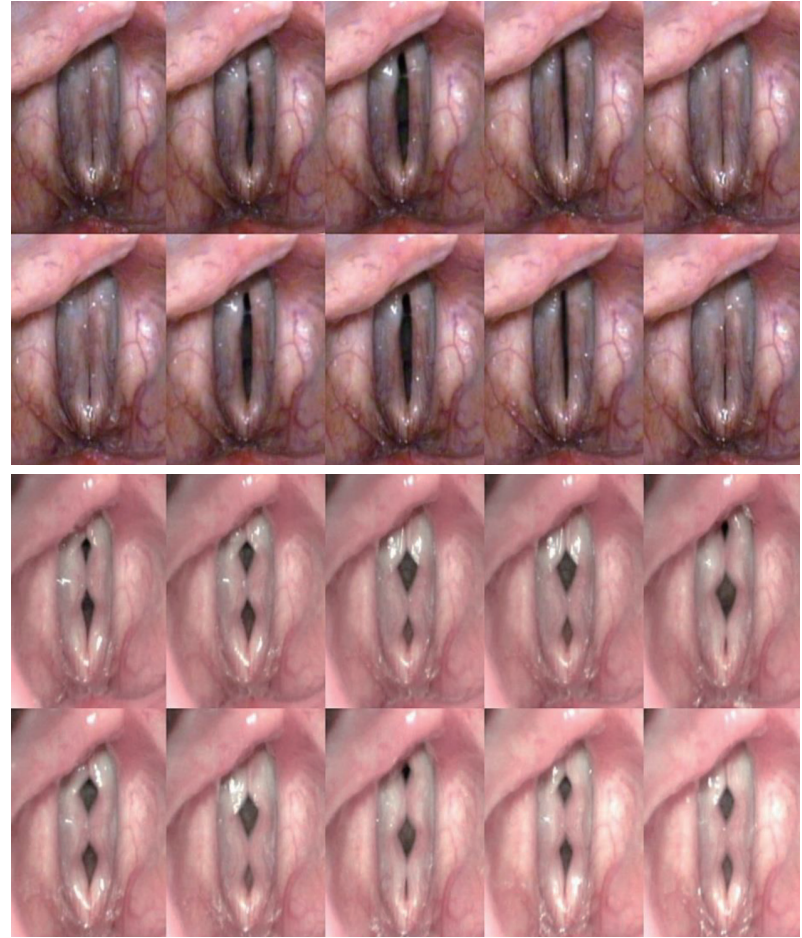

Fig. 7. Imaging findings of laryngeal videostroboscopy and the new VKG system after 4 weeks. The mucosal waves of both cords show almost normal, and the shapes of their medial peaks show normal, as determined using the new VKG system. VKG: videokymography.

단에 있어 빠른 해석이 가능하고 진단 정확도가 비교적 높았 다는 보고를 하였다. 성대 폴립, 성대마비, 근긴장성 발성장애 의 경우를 $2 \mathrm{D} \mathrm{DKG로} \mathrm{분석한} \mathrm{결과} \mathrm{공간} \mathrm{점유} \mathrm{병변이} \mathrm{있는} \mathrm{환}$ 자의 경우 보다는 일측성 성대마비와 근긴장성 발성 장애 환 자에서 의미 있는 결과를 보였다[21]. Fig. 10은 이중 음성을 가 진 우측 일측성 성대마비 환자의 $2 \mathrm{D} \mathrm{DKG}$ 영상을 보여준다.

다기능 후두성능검사시스템(Multifunctional laryngeal examination system)

최근에는 초고속 후두 비디오내시경 검사(HSV)를 비롯하 여, 라인 스캐닝 디지털 카이모그래피 검사(Line Scanning 


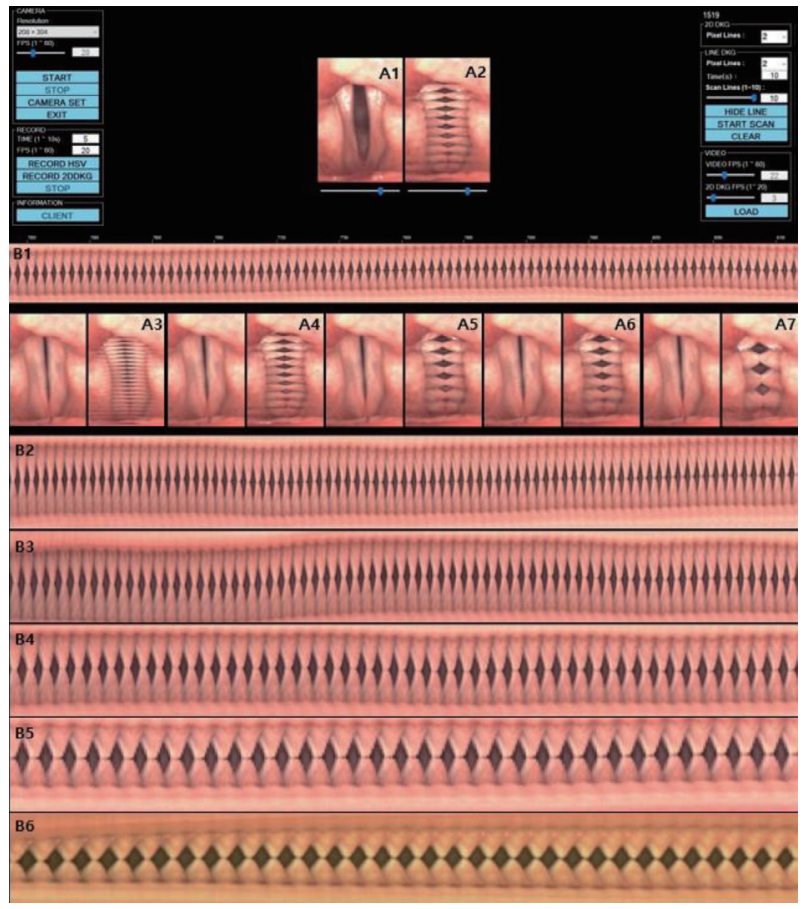

Fig. 8. Examples of real-time dual DKG and 2D DKG (normal subject, 34-year-old male). A1: navigation videoendoscopy. Example of real-time 2D DKG (A2, A3: 1 pixel line, A4: 2 pixel lines, A5: 3 pixel lines, $A 6: 4$ pixel lines, $A 7: 5$ pixel lines). Example of real-time DKG (B1, B2: 1 pixel line, B3: 2 pixel lines, B4: 3 pixel lines, B5: 4 pixel lines, B6: 5 pixel lines). 2D DKG: two-dimensional scanning digital kymography.
$\mathrm{DKG})$, 평면 스캐닝 디지털 카이모그래피 검사(2D DKG) 등 3 가지 검사를 하나의 초고속 디지털 카메라 시스템으로 촬 영하여 성대 진동을 평가할 수 있는 다기능 후두성능검사시 스템이 개발되었다. 3 가지 검사가 동시에(simultaneous) 가 능하고 단일 모니터에서 구현되기 때문에, 검사 시간의 단축, 환자의 불편감 해소뿐 아니라 3 가지 검사의 종합적 평가가 가 능하여 보다 정확한 진단이 가능하게 되었고, 이러한 검사는 실시간(quasi real-time)으로 가능하여, 즉각적인 성대 진동 평가를 할 수 있다(Fig. 11). 다기능 후두성능검사시스템은 글로 벌 셔터 방식의 초고속 Complementary Metal Oxide Semiconductor 디지털 카메라를 이용하여 셔터스피드를 $1 / 2000$ 초에서 1 초까지 설정 가능하고 별도의 의료내시경과 내시경 용 광원장치를 통해 성대의 진동 양상을 여러 가지 방법으로 촬영하는 시스템이다. 이러한 시스템을 이용하면 기능성 음 성장애, 연축성 발성장애, 성대 진전(vocal tremor), 불완전 성대마비등의 검사 및 진단에 유용할 것으로 기대된다.

\section{결 론}

음성 장애의 진단에 가장 중요한 검사는 성대 진동을 확인 하는 것이다. 후두 스트로보스코피가 성대 진동 장애의 진단 도구로 사용된 이후로 많은 기구들을 개발되었고 임상에 널
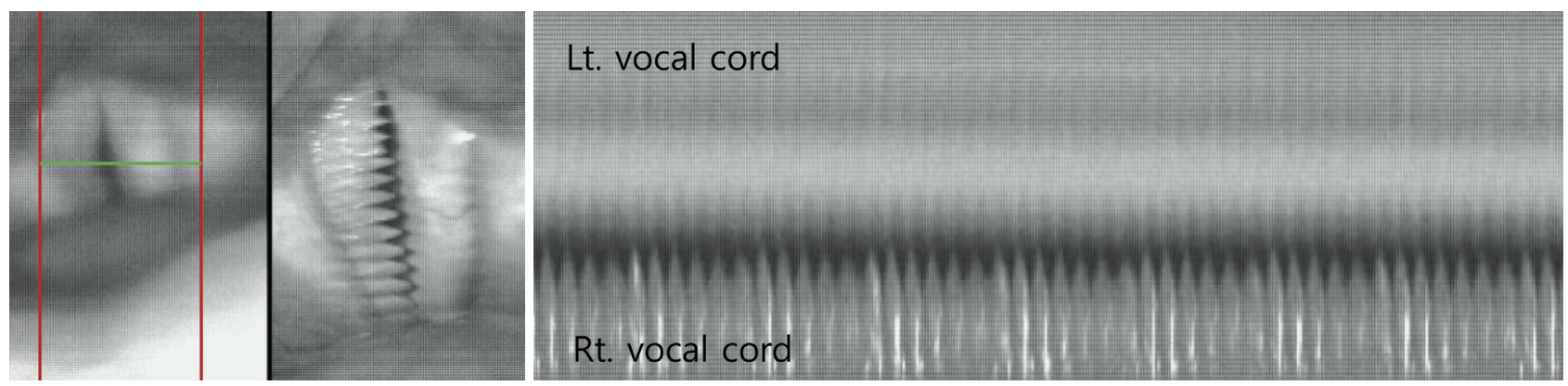

Fig. 9. Examples of real-time dual DKG and 2D DKG in patient with leftt vocal cord scar (M/50-year-old). 2D DKG: two-dimensional scanning digital kymography.

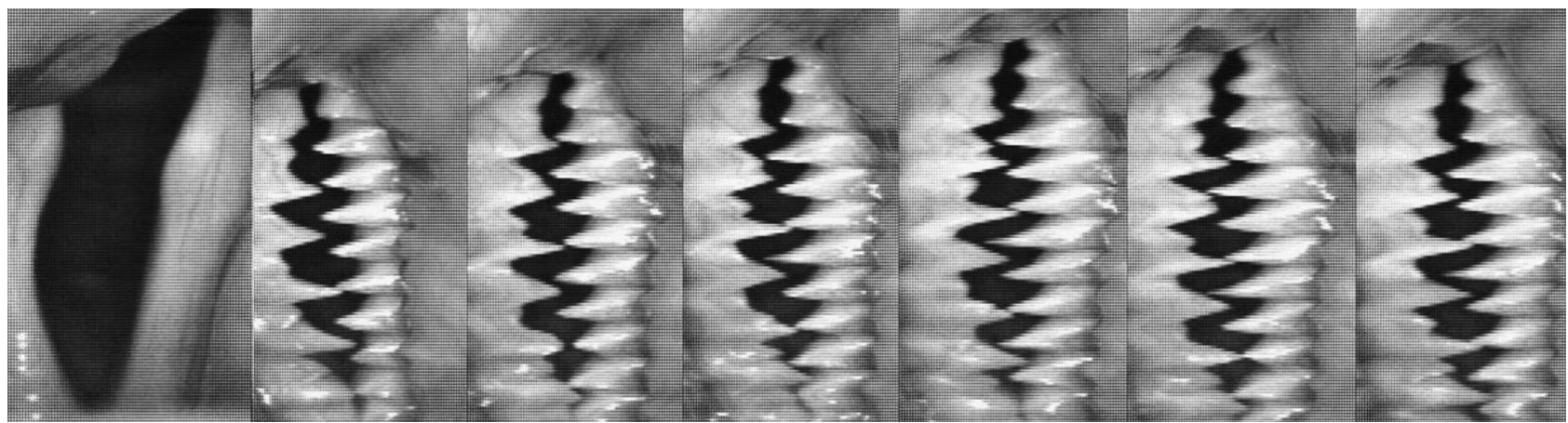

Fig. 10. Sequential image of two-dimensional scanning digital kymography in cases with diplophonia, right vocal fold palsy (left-right cords asymmetric; male/67 years old). 


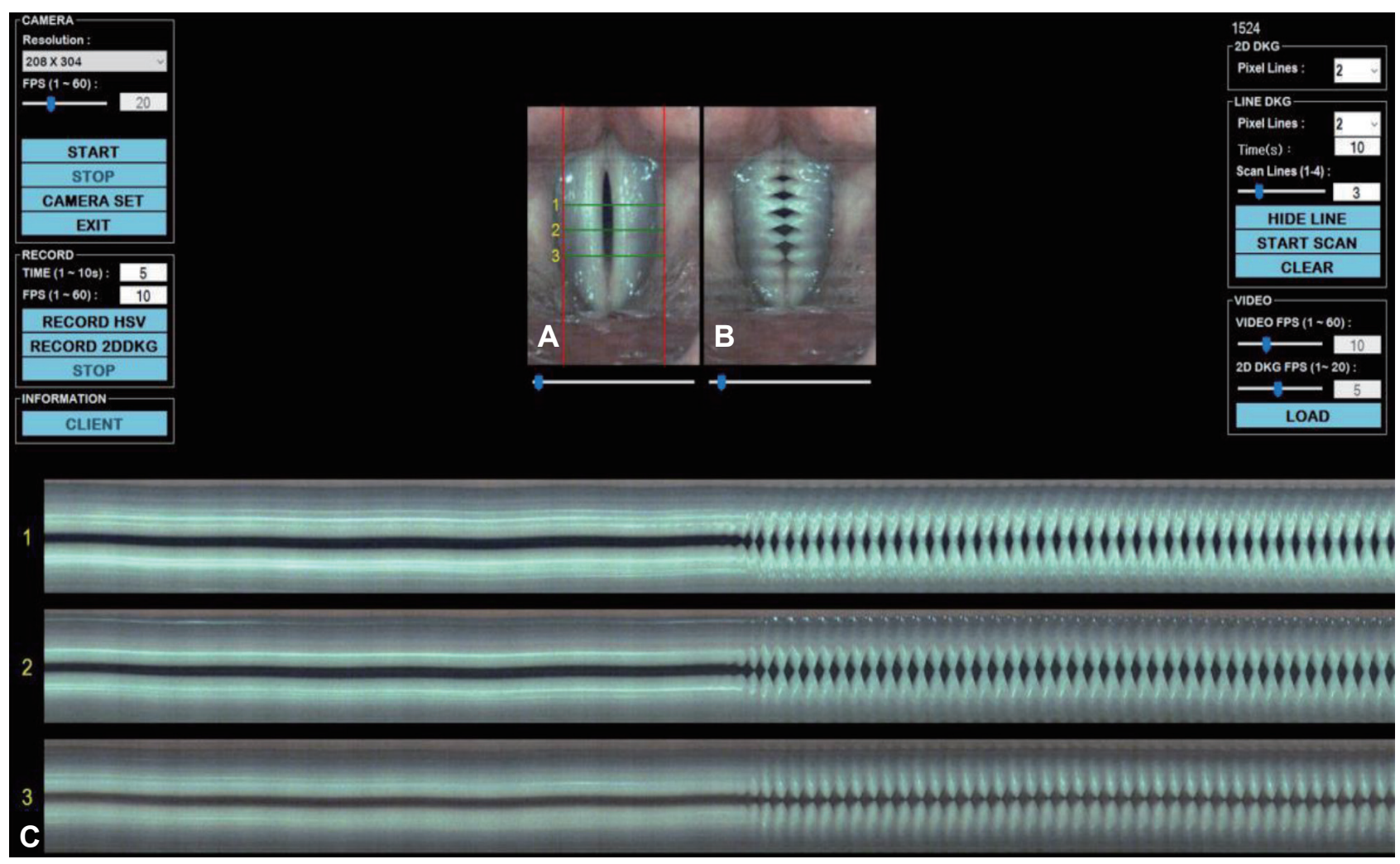

Fig. 11. Multifunctional laryngeal examination system inncludes. A: High-speed videoendoscopy. B: 2D scanning digital kymography. C: Line scanning digital kymography. Adapted from U-medical Co. catalog 2020.

리 이용되고 있다. 초고속 디지털 영상 및 초고속 비디오 내시 경, 이러한 영상을 이용한 평면 스캔 카이모그래피와 라인 스 캔 카이모그래피, 앞의 세 가지 검사를 동시에 가능한 다기능 후두성능검사시스템 등이 임상 및 연구에 이용되면서 음성장 애의 진단 영역에 많은 발전을 가져올 것으로 기대하고 있다.

중심 단어: 성대, 진동, 스트로보스코피, 카이모그래피.

Acknowledgments

This work was supported by a 2-Year Research Grant of Pusan National University.

Conflicts of Interest.

The authors have no financial conflicts of interest.

\section{Authors' Contribution}

Conceptualization: Jin-Choon Lee. Data curation: all authors. Formal analysis: all authors. Funding acquisition: Jin-Choon Lee. Investigation: all authors. Methodology: all authors. Project administration: Jin-Choon Lee. Resources: all authors. Software: Inho Bae. Supervision: Inho Bae. Validation: all authors. Visualization: all authors. Writing_original draft: Jin-Choon Lee. Writing_review \& editing: all authors. Approval of final manuscript: all authors.

\section{REFERENCES}

1. Verdonck-de Leeuw IM, Festen JM, Mahieu HF. Deviant vocal fold vibration as observed during videokymography: the effect on voice quality. J Voice 2001;15(3):313-22.
2. Cha W, Wang SG, Jang JY, Kim GH, Lee YW. Post-processing of highspeed video-laryngoscopic images to two-dimensional scanning digital kymographic images. J Korean Soc Laryngol Phoniatr Logop 2017;28(2):89-95.

3. Kang DH, Wang SG, Park HJ, Lee JC, Jeon GR, Choi IS, et al. Realtime simultaneous DKG and 2D DKG using high-speed digital camera. J Voice 2017;31(2):247.e1-7.

4. Mehta DD, Deliyski DD, Hillman RE. Commentary on why laryngeal stroboscopy really works: clarifying misconceptions surrounding Talbot's law and the persistence of vision. J Speech Lang Hear Res 2010; 53(5):1263-7.

5. Simon LL, Merz T, Dubuis S, Lieb A, Hungerbühler K. Insitu monitoring of pharmaceutical and specialty chemicals crystallization processes using endoscopy-stroboscopy and multivariate image analysis. Chem Eng Res Des 2012;90(11):1847-55.

6. Lee JC, Lee BJ, Wang SG, Roh JH, Kwon SB, Jo CW. Usefullness of the vibration pick-up in detection of pitch for synchronization of laryngeal stroboscopy. J Korean Soc Laryngol Phoniatr Logop 2007;18(1):2632.

7. Mehta DD, Hillman RE. Current role of stroboscopy in laryngeal imaging. Curr Opin Otolaryngol Head Neck Surg 2012;20(6):429-36.

8. Deliyski DD, Petrushev PP, Bonilha HS, Gerlach TT, Martin-Harris B, Hillman RE. Clinical implementation of laryngeal high-speed videoendoscopy: challenges and evolution. Folia Phoniatr Logop 2008;60: 33-44.

9. Krausert CR, Olszewski AE, Taylor LN, McMurray JS, Dailey SH, Jiang JJ. Mucosal wave measurement and visualization techniques. J Voice 2011;25:395-405.

10. Yamauchi A, Yokonishi H, Imagawa H, Sakakibara KI, Nito T, Tayama N, et al. Quantification of vocal fold vibration in various laryngeal disorders using high-speed digital imaging. J Voice 2016;30(2): 
JKSLP

205-14.

11. Yamauchi A, Yokonishi H, Imagawa H, Sakakibara KI, Nito T, Tayama N, et al. Characterization of vocal fold vibration in sulcus vocalis using high-speed digital imaging. J Speech Lang Hear Res 2017;60(1): 24-37.

12. Yamauchi A, Yokonishi H, Imagawa H, Sakakibara KI, Nito T, Tayama N, et al. Visualization and estimation of vibratory disturbance in vocal fold scar using high-speed digital imaging. J Voice 2016;30(4): 493-500.

13. Yamauchi A, Yokonishi H, Imagawa H, Sakakibara KI, Nito T, Tayama N. Quantitative analysis of vocal fold vibration in vocal fold paralysis with the use of high-speed digital imaging. J Voice 2016;30(6): 766.e13-22.

14. Sekimoto S, Tsunoda K, Kana K, Makiyama K, Tsunoda A, Kondo K, et al. Commercially available high-speed system for recording and monitoring vocal fold vibrations. Act Otolaryngol 2009;129(12): 1524-6.

15. Bonilha HS, Deliyski DD, Gerlach TT. Phase asymmetries in normophonic speakers: visual judgments and objective findings. Am J Speech
Lang Pathol 2008;17(4):367-76.

16. Tinges M, Wittenberg T, Mergell P, Eysholdt U. Imaging of vocal fold vibration by digital multi-plane kymography. Comput Med Imaging Graph 1999;23(6):323-30.

17. Sec JG, Sham F, Schutte HK. Videokymography. In: Fried M, Ferlito A, editors. The Larynx. 3rd ed. San Diego: Plural Publishing;2009. p. 253-71.

18. Svec JG, Sam F, Schutte HK. Videokymography in voice disorders: what to look for?. Ann Otol Rhinol Laryngol 2007;116(3):172-80.

19. Qu Q, Schutte HK, Gu L, Mu Q. An automatic method to quantify the vibration properties of human vocal folds via videokymography. Folia Phoniatr Logo 2003;55(3):128-36.

20. Wang SG, Park HJ, Lee BJ, Lee SM, Ko B, Lee SM, et al. A new videokymograph system for evaluation of the vibration pattern of entire vocal folds. Auric Nasus Larynx 2016;43(3):315-21.

21. Be IH, Wang SG, Kwon SB, Kim ST, Sung ES, Lee JC. Clinical application of two-dimensional scanning digital kymography in discrimination of diplophonia. J Speech Lang Hear Res 2019;62(10): 3643-54.

8 